in a foreword that it provides a plan of central Liverpool which would make it a place worthy of the coming needs of post-war building on a grand scale. The broad street or avenue making a circuit from pier-head to pier-head, connecting the three railway stations and forming a ring from which traffic could easily move to the outskirts without crowding the centre as at present, would give an importance to the inner section of the City which it sadly lacks to-day. Moreover, the re-planning of the pier-head itself would give Liverpool at last a water-front of which it might be proud, and through which it would proudly welcome travellers from all parts of the globe.

The first proposal covers the dock area, whereby the Dock Road, north of its junction with King Edward Street, would virtually become a private service road on a combined dock and railway estate, extending the existing dock estate eastwards to Derby Road and Great Howard Street. These two roads would be converted into a wide artery capable of carrying all north- and south-bound through traffic along the line of the North Docks, and the Overhead Railway would be replaced by a more mobile system of passenger traffic.

A major item in the plan is an inner ring road which is regarded as the proposal which could confer the greatest benefit to the heart of Liverpool. It is a feature missing in the natural development of most towns. It would give added importance to Exchange Station, and the scope for architectural treatment which the expansion of the railway termini afford is greatly stressed by Alderman Shennan. There would be a direct connexion between Exchange Station and the Lord Street-Church Street shopping centre, while the proposals for the new civic centre, the heart of which is the tunnel entrance, provide for the reservation of the St. John's Lane frontage for civic buildings, to balance the Museum and Art Gallery, and to complete the growing of the stately beauty of St. George's Hall, while on the western side, buildings connected with the administration of the City would be sited.

The town hall, the two cathedrals and the pierhead are the subject of other planning proposals, and the scheme contemplates a general rectification of the existing street plan, control by zoning, provision of industrial sites, open spaces and linking the parks. The plan involves a long-term as well as a shortterm policy.

There is no reason to doubt the ability of the people of Great Britain to seize the opportunities of replanning which the War has given us, and these two examples of plans show a vision and vigour which are the best safeguard against the apathy and selfishness which led to London missing its opportunity of nearly three centuries ago.

\section{ELECTRICAL PRODUCTION OF BULLET-PROOF STEEL}

$\mathrm{T}$ HE manufacture of bullet-proof steel is surveyed in an article by A. G. Arend in the Electrician of July 31. Formerly intended for helmets, bulletproof steel was also made for breastplates in the closing stages of the War of 1914-18. When the latter were first proposed, a manganese-vanadium steel was employed containing some 0.90 per cent of man- ganese and $0 \cdot 20$ per cent of vanadium, and was prepared in Heroult three-phase electric furnacess Despite the purest possible metal being produced, results were not uniform, and a manganese steel was substituted containing 12 per cent of manganese, and I per cent of carbon.

Little has been done in the intervening years in the way of development, although vanadium steels have found extended use in automobile production. A maximum of 0.02 per cent is allowed for both sulphur and phosphorus; the small range of the other constituents precludes the use of anything but the absolute precision of control peculiar to the electric furnace. The vanadium constituent is important, and although ranging only from $0 \cdot 15$ to 0.25 per cent content, it allows of a light strong steel. The last approved bullet-proof steel, prepared in 6-ton Heroult furnaces, contained 2 per cent nickel, I per cent manganese, $0 \cdot 20$ per cent vanadium, $0 \cdot 20$ per cent silicon, 0.02 per cent phosphorus, 0.02 per cent sulphur and 0.42 per cent carbon. The admissible error was 0.05 per cent except with sulphur and phosphorus, which could not exceed the 0.02 per cent maximum.

The furnaces were not then equipped with automatic arc regulation, and gave trouble in the initial melting of scrap. Present-day furnaces are of smaller capacity and bottom connexions are omitted in the larger sizes to avoid the formation of cracks. Water cooling of bottom connexions, so far as the hearth is concerned, is now regarded as potentially dangerous.

There is a choice of design to-day betwoen the direct arc and arc-resistance types of furnaces, the latter being preferred when a smaller charge suffices. Troubles with the smaller electrodes for 1-ton hearths resulted in the use of two-phase furnaces with bottom connexions, the current heing supplied through Scott connected transformers. In comparison with the low operating voltages used for plain carbon steels, supply is usually switched on at 110 volts : with the cold scrap used in the chargo, surging can momentarily raise the current as high as $10,000 \mathrm{amp}$. Since the refining period tends to vary, the energy consumption rangas from 750 to $825 \mathrm{kwh}$. per ton.

The carbon content following de-phosphorizing should be about $0 \cdot 300$ per cent, with the actual phosphorus below 0.02 per cent. Tapping temperature is important and after final additions have been made to the melt, it is only allowed to remain in the ladle long enough for the slag to rise properly, whereupon it is cast into ingots of about 8 in. by $14 \mathrm{in}$. cross. section, care being taken to avoid undue strains from shrinkage by chilling. Ingots are then rolled and shaped as required, undergoing any necessary heat treatment.

During 1914-18, two test methods were available for holmets and breastplates. The former, which were of $0.035 \mathrm{in}$. sheot, were subjected to the impact at $10 \mathrm{ft}$. of a bullet fired from a 0.44 Colt revolver with a muzzle velocity of $840 \mathrm{ft} . / \mathrm{sec}$. The breast. plates, of 0.175 in. thickness, were expected to withstand the impact of a copper-sheathed rifle bullet fired at $50 \mathrm{yd}$. with a muzzle velocity of $2,140 \mathrm{ft}$. $/ \mathrm{sec}$. In the former case the metal was considered to be satisfactory if the bullet did not make a dent of more than $0.5 \mathrm{in}$. in depth and $3.5 \mathrm{in}$. in diameter. Successful production of bullet-proof steel largely depends upon systematic furnace operation, and it is imperative that all electrical connexions function with precision to permit of continuous uniform work ing without temporary stoppages. 